\title{
Neuronal Responses to Lemniscal Stimulation in Laminar Brain Slices of the Inferior Colliculus
}

\author{
Shobhana Sivaramakrishnan and Douglas L. Oliver \\ Department of Neuroscience, University of Connecticut Health Center, Farmington, CT 06030-3401, USA
}

Received: 8 April 2005; Accepted: 31 August 2005; Online publication: 20 October 2005

\begin{abstract}
The central nucleus of the inferior colliculus (ICC) receives inputs from all parts of the auditory brainstem and transmits the information to the forebrain. Fibrodendritic laminae of the ICC provide a structural basis for a tonotopic organization, and the interaction of inputs within a single layer is important for ICC processing. Transverse slice planes of the ICC sever the layers and many of the ascending axons that enter through the lateral lemniscus. Consequently, the activity initiated within a lamina by a pure lemniscal stimulus is not well characterized. Here, we use a slice plane that maintains the integrity of the laminae in ICC and allows the axons in the lateral lemniscus to be stimulated at a distance from the ICC. We examined both the postsynaptic currents and potentials of the same neurons to lemniscal stimuli in this laminar brain slice. Our main finding is that lemniscal stimulation evokes prolonged synaptic potentials in ICC neurons. Synaptic potential amplitudes and durations increase with lemniscal shock strength. In $\sim 50 \%$ of ICC neurons, the postsynaptic potential is equal in duration to the postsynaptic current, whereas in the remaining neurons it is three to four times longer. Synaptic responses to single shocks or shock trains exhibit plateau potentials that enable sustained firing in ICC neurons. Plateau potentials are evoked by $\mathrm{N}$-methyl-D-aspartate (NMDA) receptor activation, and their amplitudes and durations are regulated by both NMDA-R and gamma-aminobutyric acid A $\left(\mathrm{GABA}_{\mathrm{A}}\right)-\mathrm{R}$ activation. These data suggest that in the intact laminae of the
\end{abstract}

Correspondence to: Shobhana Sivaramakrishnan - Department of Neuroscience - University of Connecticut Health Center · Farmington, CT 06030-3401, USA. Telephone: (860)-679-2241; fax: (860)-679-8766; email: shobhana@neuron.uchc.edu
ICC, lemniscal inputs initiate sustained firing through monosynaptic and polysynaptic NMDA-mediated synapses regulated by $\mathrm{GABA}_{\mathrm{A}}$ synapses.

Keywords: AMPA, NMDA, GABA, auditory pathways, brain slice, lateral lemniscus, lamina, inferior colliculus

\section{INTRODUCTION}

The central nucleus of the inferior colliculus (ICC) is a critical part of the central auditory pathway. Axons from virtually every part of the lower auditory brainstem ascend to the lateral lemniscus and synapse on neurons of the ICC (Oliver and Huerta 1992; Oliver 2000; Loftus et al. 2004). Major excitatory synaptic inputs to ICC neurons come from the dorsal and ventral cochlear nuclei and the medial and lateral superior olive. At the same time, ICC neurons receive ascending inhibitory inputs from the lateral superior olive and the nuclei of the lateral lemniscus (Adams 1979; Saint Marie et al. 1989; Shneiderman et al. 1993; Riquelme et al. 2001). This combination of excitatory and inhibitory inputs ascending through the lateral lemniscus is one of several unique and important characteristics of the ICC.

The activation of excitatory and inhibitory synapses on ICC neurons during sound stimulation has been demonstrated by a few intracellular and wholecell recordings from ICC neurons in vivo (Torterolo et al. 1995; Covey et al. 1996; Kuwada et al. 1997; Pedemonte et al. 1997); however, most studies on excitation and inhibition in ICC have relied on extracellular recording techniques (Faingold et al. 1993; Park and Pollak 1993a, b; Le Beau et al. 1996; Palombi and Caspary 1996; Casseday et al. 2000; 
Sivaramakrishnan et al. 2004). Experiments in brain slices offer a controlled environment for the activation of synaptic inputs to ICC neurons and have allowed the pharmacological isolation and identification of specific synaptic currents (Moore et al. 1998; Ma et al. 2002a, b; Wu et al. 2002, 2004).

Fibrodendritic layers of ICC (Morest and Oliver 1984; Faye-Lund and Osen 1985) provide a structural basis for a tonotopic organization (Schreiner and Langner 1997). The layers are composed of the dendrites of highly oriented, flat, disk-shaped neurons (Morest and Oliver 1984; Malmierca et al. 1993), the main cell type in ICC, and parallel axons (Fig. 1). The main inputs to the layers are the axons from the lateral lemniscus. Because of the narrow width, but long length and height of each layer, the inputs to one layer may synapse on an array of neurons in that layer (Fig. 1D). The layers in ICC also contain local axons from other ICC neurons that interconnect most neurons in that layer (Fig. 1D); (Oliver et al. 1991).

ICC laminae complicate the study of synaptic physiology. Most brain slice experiments in the rat ICC have been performed on transverse slices (Smith 1992; Li et al. 1994, 1998, 1999; Bal et al. 2002; Kraushaar and Backus 2002; Ma et al. 2002a, b; Wu et al. 2002; N'Gouemo and Morad 2003; Wu et al. 2004), cut roughly perpendicular to the ICC layers. Because that plane cuts the laminae, it is likely to sever the dendrites of the flat cells and will cut many

A

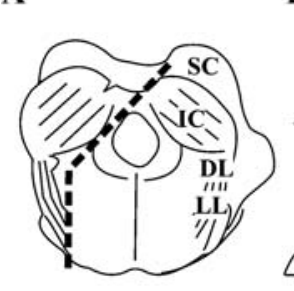

B

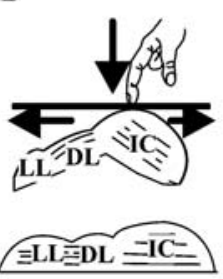

C

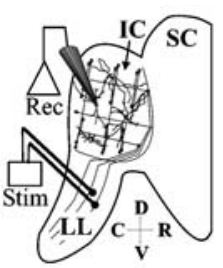

D

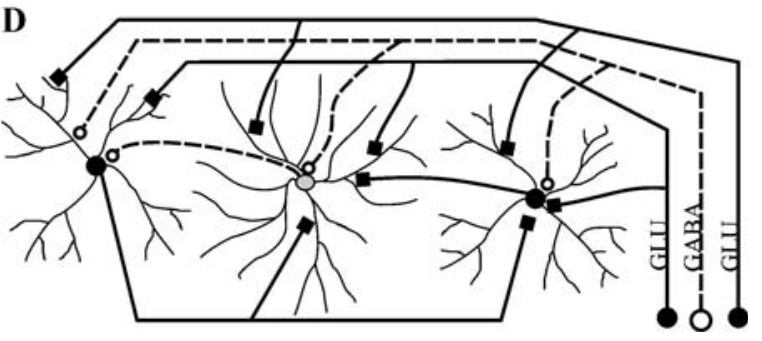

FIG. 1. Laminar slice plane of the ICC. (A) Cuts (dotted line) are made parallel to the lateral lemniscus and layers of the ICC in a transverse block of the brainstem. (B) Method of flattening the slice so that lemniscal axons become parallel with the layers in the ICC; lower figure shows the orientation for slicing. (C) Slice with stimulation (Stim) and recording ( $\mathrm{Rec}$ ) configurations. (D) Circuit diagram of a single layer in ICC after cutting in the laminar slice plane. SC: superior colliculus, ICC: central nucleus of the inferior colliculus, DL: dorsal nucleus of the lateral lemniscus, LL: lateral lemniscus. Direction arrows: dorsal, ventral, rostral, and caudal. inputs to the ICC, particularly those entering from the lateral lemniscus. This has not been a problem for previous studies focused on the dorsal cortex of IC, because commissural inputs were not cut (Smith 1992; Li et al. 1994, 1998, 1999). When using the transverse plane, the stimulating electrodes must be placed inside the ventrolateral part of ICC (Wu et al. 2002, 2004) or just outside it (Wagner, 1996; Moore et al. 1998). This makes it likely that local IC axons are directly stimulated in addition to axons from the lateral lemniscus.

Stimulation of the axons in the lateral lemniscus is required in studying the inputs to ICC. Here, we use a new slice plane, called the laminar plane, to examine the events initiated by the axons of the lateral lemniscus that terminate in a single layer of ICC. Our observations include the synaptic currents, postsynaptic potentials, and the firing patterns of neurons that occur within an ICC lamina. Our results suggest that the sustained firing of ICC neurons requires prolonged NMDA-mediated plateau potentials that are initiated by lemniscal inputs, and these are regulated by $\mathrm{GABA}_{\mathrm{A}}$ inputs.

\section{MATERIALS AND METHODS}

Long-Evans rats, 11-17 days old, were used for this study. During this postnatal period, we did not observe systematic changes in synaptic responses and neuronal firing patterns with age, and the pharmacological agents used appeared to be equally effective at 11 and 17 postnatal days. Experiments were carried out in accordance with NIH Guidelines and protocols approved by the Animal Care Committee of the University of Connecticut Health Center.

Rats were anesthetized with a mixture of ketamine/xylazine and then decapitated. A block containing the ICC was removed from the brain with two transverse cuts. Two additional cuts were made, a cut parallel to the lateral lemniscus in the parasagittal plane and a second one at $45^{\circ}$ to the sagittal plane, parallel to the laminae of the ICC (Fig. 1A, dotted lines). The cut surface was oriented so that the lemniscus and ICC were in the same plane (Fig. 1B) and glued onto the stage of a Vibratome (Ted Pella, USA). Brain slices of 300- $\mu \mathrm{m}$ thickness were cut, and then allowed to recover for an hour in warm $\left(35^{\circ} \mathrm{C}\right)$, oxygenated $\left(95 \% \mathrm{O}_{2} / 5 \% \mathrm{CO}_{2}\right)$ saline. For recording, individual slices were transferred to a Peltier-driven slice chamber (model PSMI; Medical Systems, USA) fixed to the stage of an upright microscope (Zeiss Axioskop) fitted with a water immersion objective $(\times 40 /$ NA 0.75$)$ and differential interference optics. Experiments were carried out at $35^{\circ} \mathrm{C}$, and the slice was continuously superfused with oxygenated saline 
(in mM: $120 \mathrm{NaCl}, 5 \mathrm{KCl}, 2.4 \mathrm{CaCl}_{2}, 1.3 \mathrm{MgSO}_{4}, 1$ $\mathrm{KH}_{2} \mathrm{PO} 4,26 \mathrm{NaHCO}_{3}, 25$ glucose, $\mathrm{pH}$ 7.3). An antagonist of NMDA receptors (D,L-5-amino-phosphonovaleric acid, APV, 20-100 $\mu \mathrm{M})$, an antagonist of AMPA receptors [2,3-dihydroxy-6-nitro-7-sulfamoylbenzo (F) quinoxaline, NBQX, $10 \mu \mathrm{M}$ ], and an antagonist of $\mathrm{GABA}_{\mathrm{A}}$ receptors (bicuculline, 10-50 $\mu \mathrm{M}$ ), were obtained from Sigma-Aldrich, dissolved in the external saline, and bath applied. The concentration of bicuculline used did not cause changes in resting membrane potentials. Bicuculline also affects apamin-sensitive, calcium-activated potassium channels (Khawaled et al. 1999). Because these channels are found in the ICG (Sivaramakrishnan and Oliver 2001), we tested the effect of bicuculline on firing patterns across cell types. At the concentrations used, bicuculline did not affect interspike intervals or rates of firing evoked by $600 \mathrm{~ms}$ current steps injected into the soma $(n=15)$.

Whole-cell patch-clamp techniques were used in current-clamp and voltage-clamp modes on the same cell. Recordings were made with patch pipettes of 5-7 $\mathrm{M} \Omega$ resistance made from borosilicate glass $\left(K_{\mathrm{i} \max }\right.$, $1.5 \mathrm{~mm}$ O.D.). Pipettes were filled with a solution containing the following (in $\mathrm{mM}$ ): $120 \mathrm{~K}$ Gluconate, $5 \mathrm{NaCl}, 2$ EGTA, $0.1 \mathrm{CaCl}_{2}, 5 \mathrm{Mg}$-ATP, $0.3 \mathrm{Na}$-GTP, 10 HEPES, pH 7.3. In some instances, $10 \mathrm{mM}$ QX-314 was added to the internal solution to block voltagedependent sodium channels and prevent spiking. An EPC-8 amplifier (HEKA Elektroniks/Instrutech Corporation) was used for both current- and voltageclamp recordings and PClamp software (Axon Instruments, Foster City, CA, USA) was used for data collection and analyses. Junction potentials between the ground and recording electrodes as well as liquid junction potentials between the pipette and external solutions $(+10 \mathrm{mV})$ were compensated before the whole-cell patch mode was established. Series resistances were generally $12-18 \mathrm{M} \Omega$ and were compensated by $80-85 \%$. Recordings with higher series resistances or lower compensation were not included in the analyses. Data were filtered at $5 \mathrm{kHz}$ during acquisition. Synaptic activity was evoked by stimulating the lateral lemniscus with an extracellular bipolar tungsten electrode placed on the nerve bundle ventral to the inferior colliculus (Fig. 1C).

Before study with synaptic stimulation, all neurons were tested with intracellular injection of current under current clamp mode to identify discharge patterns related to different intrinsic membrane properties (Sivaramakrishnan and Oliver 2001). Responses to depolarizing currents were previously defined as regular, adapting, or transient. Responses to hyperpolarizing or prehyperpolarizing currents were defined previously as rebound, nonrebound, or pause-build.

\section{RESULTS}

Responses to single shocks in the laminar slice plane

Single electrical shocks $(0.2-0.5 \mathrm{~ms})$ to the lateral lemniscus in the laminar brain slice (see Fig. 1C for electrode placement) evoked net excitatory synaptic activity that increased in duration and amplitude with increasing stimulus levels. Lemniscal stimulation evoked a net excitatory postsynaptic potential (PSP) (Fig. 2A). In recordings with QX-314 in the internal solution $(n=7)$, the PSP durations and amplitudes can be seen clearly because the action potentials are blocked. For example, in the neuron illustrated in Figure 2A, the duration of the smallest PSP evoked by a low shock strength was $200 \mathrm{~ms}$, and the largest PSP evoked by the maximum shock strength used lasted for over $1 \mathrm{~s}$ (Figs. 2A-B). A prolonged plateau phase (Fig. 2A, arrow, top trace) was often observed during the larger PSPs in this and other neurons.

Recordings without QX-314 in a larger population of neurons $(n=81)$ showed a similar net excitatory PSP. Most cells (77/81) exhibited only depolarizing PSPs to single shocks, whereas others exhibited a small hyperpolarizing PSP either leading or following a depolarizing PSP. At low shock strengths, PSPs had durations at least $50-75 \mathrm{~ms}$.

An increase in the duration and amplitude of postsynaptic currents (PSCs) was also observed in ICC neurons as the number of lemniscal inputs increased with higher-strength stimulus levels. These PSCs were inward when the cell was held at its normal resting potential (usually -50 to $-60 \mathrm{mV}$ ). At high stimulus strengths, these inward PSCs were much larger than would be expected for IPSCs alone (IPSCs were $\sim 250 \mathrm{pA}$; see Fig. 4), demonstrating that the net input balance shifted toward excitation as more inputs were recruited. The increase in PSC amplitude and duration occurred in all ICC neurons examined $(n=63)$, and it was partly attributable to a summation of temporally separate inputs that occurred with increasing shock strength. For example, Figure 2C (top trace) shows temporally distinct PSCs at the lowest shock level that merge when higher shock levels were used (Fig. 2C, second and third traces from top). Increasing levels of stimulation further lengthened the duration of the PSC and increased the amplitude. This occurred in all ICC neurons examined $(n=63)$.

\section{Input-output relationships}

To investigate the relationship of the membrane potential to the input, we compared the PSC (input) and the PSP (output) evoked by the same stimulus and at the same holding and resting potentials. 
A

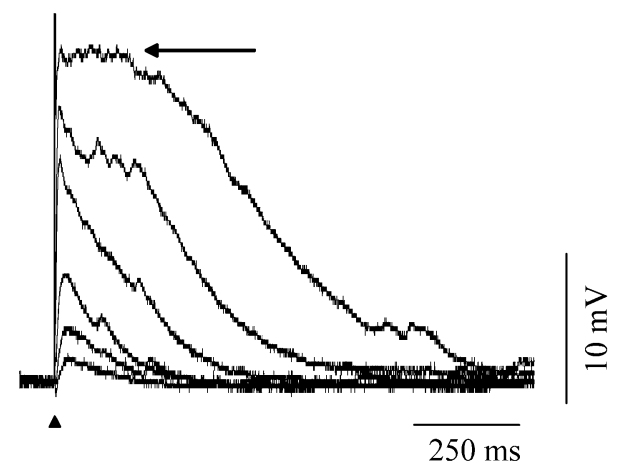

B

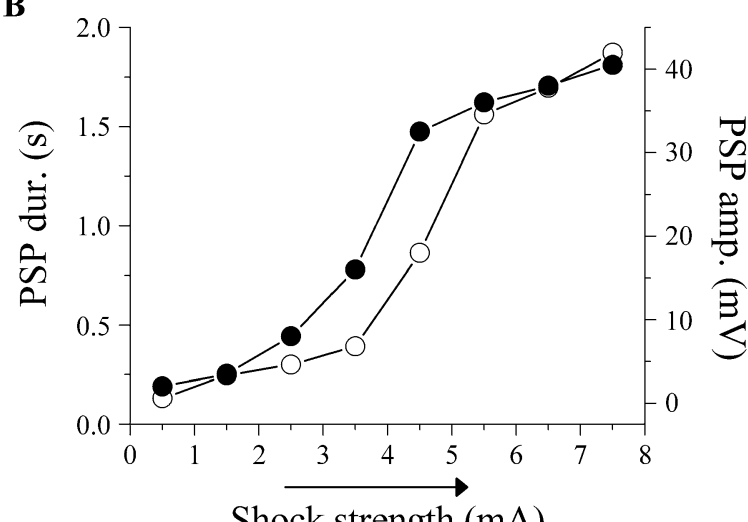

C
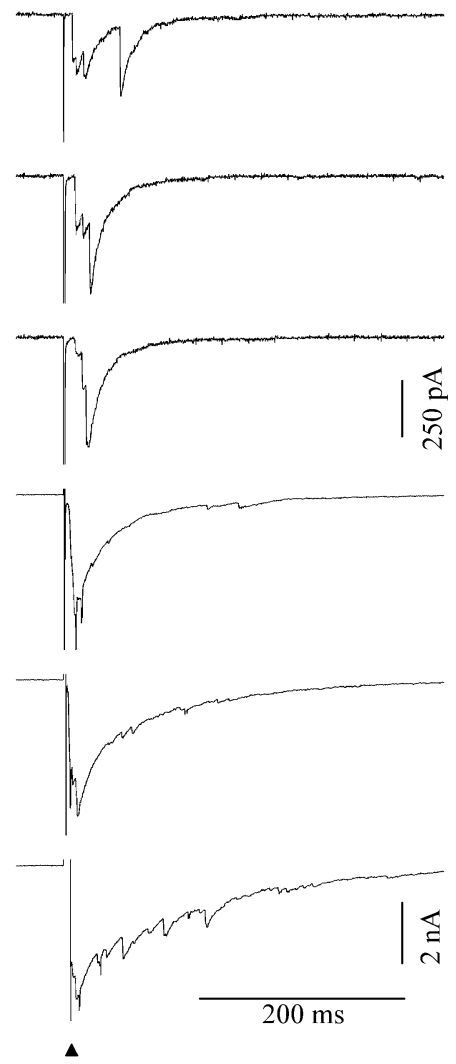

FIG. 2. Responses of ICC neurons to synaptic recruitment. (A) PSPS evoked in a neuron (P14) by increasing shock strengths when 10 $\mathrm{mM}$ QX-314 was present in the internal solution of the electrode. Bottom to top traces are responses to increasing shock strengths. Vertical arrow: stimulus artifact. Horizontal arrow (top trace): plateau region of the PSP. (B) PSP amplitude (filled circles) and

Ratios of the PSP to the PSC durations were calculated as the slope of the paired measurements made over the full range of stimulus strengths in a single neuron. Figure 3 illustrates the input-output functions for the three ICC neuron types: sustainedregular, rebound-adapting, and rebound-transient, identified by their responses to depolarizing and hyperpolarizing current injections (Fig. 3Ai). These cell types make up $19 \%, 25 \%$, and $21 \%$, respectively, of the total neuron population in the ICC (Sivaramakrishnan and Oliver 2001).

ICC neurons responded in one of two modes. Some neurons had PSP durations that were three to four times longer than the PSC durations. For example, sustained regular (SR) neurons had PSP durations that exceeded the PSC duration at both high and low shock strengths (Fig. 3Aii-iii) and the sustained firing of action potentials also extended beyond the PSC (Fig. 3Aii, left column, upper trace). PSP durations in SR cells were a steep function of PSC duration (slope of 3) (Fig. $3 \mathrm{Bi}, n=8$ ), and the total duration of spiking was about twice as long as duration (open circles) as a function of shock strength for the cell shown in (A). (C) PSCs recorded in normal saline at increasing shock strengths (top to bottom) in a rebound-regular (RR) cell (P12). Shock strengths ranged from 1 to $6 \mathrm{~mA}$. The vertical scale bar for the top three traces is $250 \mathrm{pA}$, whereas the scale bar for the bottom three traces is $2 \mathrm{nA}$. Holding potential in (C) is $-60 \mathrm{mV}$.

PSC duration (Fig. 3C, triangles; slope of 2; $n=8$ ). Pause-build cells (Sivaramakrishnan and Oliver 2001) showed similarly steep input-output functions $(n=$ 13; data not shown).

In contrast, in other ICC neurons, PSP and PSC durations were similar. For example, rebound-adapting (RA) and rebound-transient (RT) neurons had similar PSP and PSC durations at both subthreshold (Fig. 3Aiii, middle and right columns, respectively; lower traces) and suprathreshold stimulus levels (Fig. 3Aii, middle and right columns, respectively; upper traces). Such neurons had PSP/PSC slopes near 1 (Fig. 3Bii, RA $n=11$; Fig. 3Biii, RT $n=6$ ). As predicted from the PSP/PSC ratio, the duration of spiking was roughly equal to the duration of the PSC in these cells (Fig. 3C, circles; slope of 1).

ICC cell types exhibit differences in input resistance. For example, sustained-regular cells have input resistances of $\sim 300 \mathrm{M} \Omega$, whereas the rebound class of neurons has a lower input resistance $(\sim 110 \mathrm{M} \Omega)$ (Peruzzi et al. 2000). Measurements of passive membrane time constants showed parallel differ- 
A
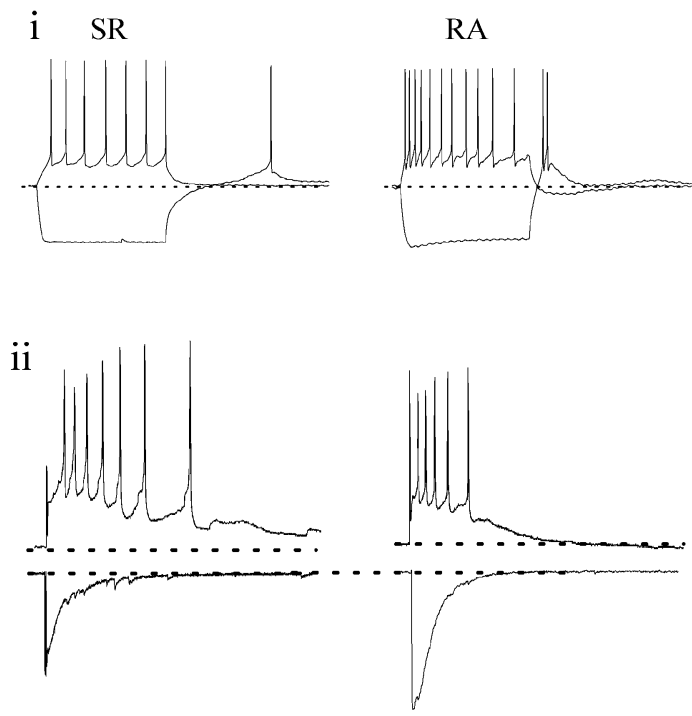

iii

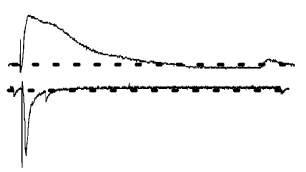

B

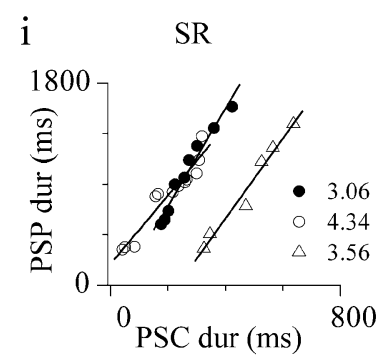

C
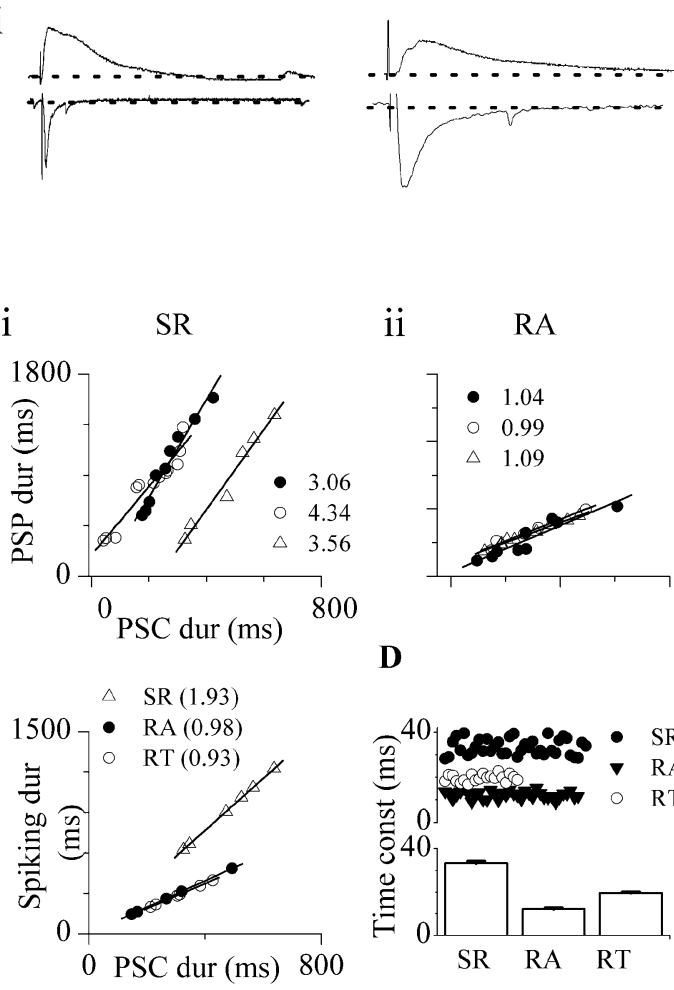

ii

RA

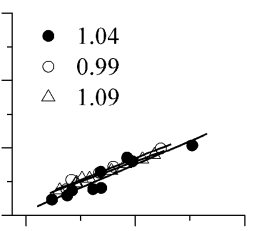

D

RA
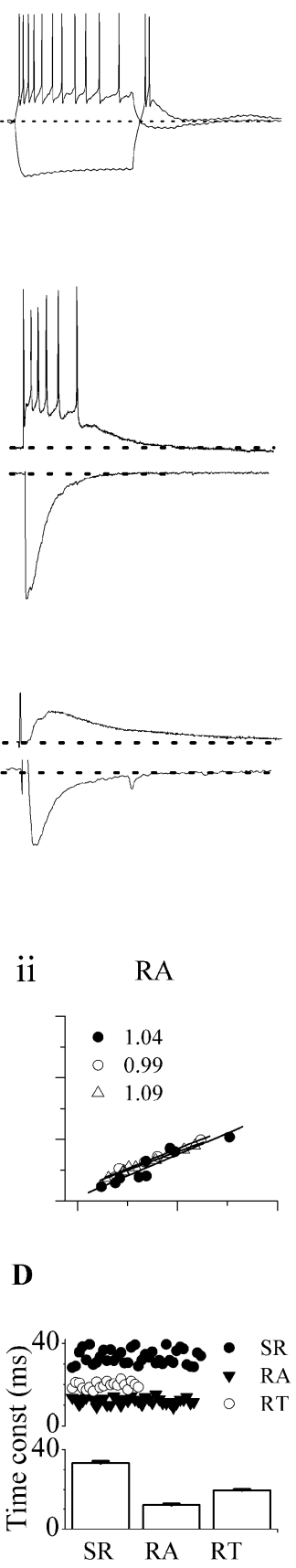

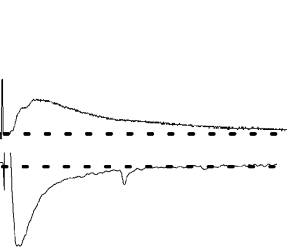

RT
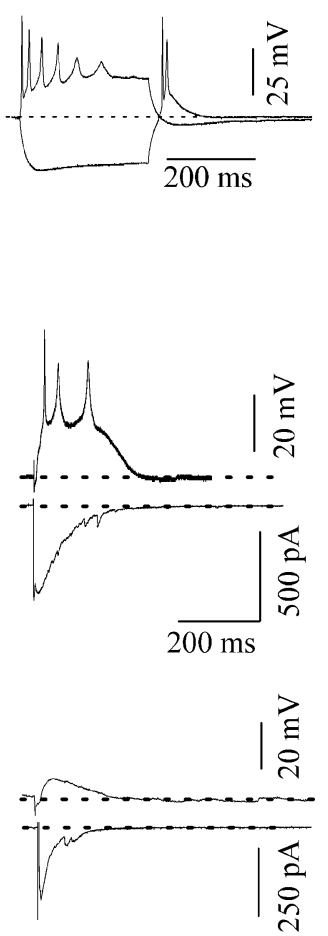

iii

RT

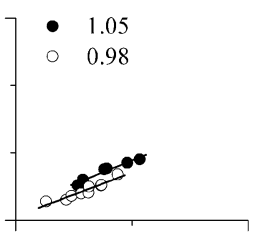

$\mathbf{E}$

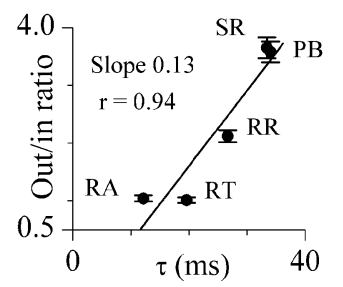

FIG. 3. Input-output relationships in ICC neurons. (Ai) Intrinsic response patterns of IC neurons to depolarizing and hyperpolarizing current steps $(300 \mathrm{~ms})$ injected into the soma. (Aii) Responses in the same cell types to lemniscal stimulation. Suprathreshold PSPs (top) and the corresponding PSC (bottom) in three neurons. (Aiii) Subthreshold PSPs and the corresponding PSCs. Ages: SR, P12; RA, P11; RT, P14. (B) Plots of PSP duration as a function of PSC duration for SR, RA, or RT neurons. In each plot, the PSP-PSC relation is shown for more than one cell $(n=8)$. The numbers by each plot indicate the slopes of each line in the plot. Slopes are in parentheses. (C) Comparison of the total duration of spiking with the PSC duration for one cell of each type. PSCs were randomly selected and the corresponding responses in current-clamp used for the total spike duration. Neuron labels assigned according to previously character- ized responses to current injection (Sivaramakrishnan and Oliver, 2001). SR, sustained-regular; RA, rebound-adapting; RT, reboundtransient. (D) Top panel: scatter plots of membrane time constants of ICC neurons. Time constants were measured by exponential fits of the voltage responses to small 300-ms hyperpolarizing current steps (Sivaramakrishnan and Oliver, 2001). Bottom panel: average time constants from 38 sustained-regular cells, 36 rebound-adapting cells, and 20 rebound-transient cells. Ages ranged from P11 to P17. (E) Plot of the average slopes of the output/input ratio (as plotted in $\mathrm{Bi}-$ iii) against the average time constant for the five ICC cell types that exhibit some degree of sustained firing during a synaptic input. SR: sustained-regular (13 cells), PB: pausebuild (11 cells), RR: reboundregular (11 cells), RT: rebound-transient (14 cells), RA: reboundadapting (13 cells). Error bars represent SD. 
ences in ICC cells (Fig. 3D). In all ICC cells, membrane time constants exceeded $10 \mathrm{~ms}$; within a cell type, time constant values showed little scatter in the population (Fig. 3D, top panel; three cell types shown). Time constants ranged from a low of $12 \pm 3$ ms (SD) in rebound-adapting cells $(n=36$; Fig. 3D, bottom panel) to a high of $33 \pm 6 \mathrm{~ms}$ (SD) in sustained-regular cells $(n=38$; Fig. 3D, bottom panel). We examined the correlation between membrane time constants and the slopes of the output/input curves for the different ICC cell types (Fig. 3E). The output/input slope showed a general tendency to increase with the time constant, thus cells with longer time constants, such as the sustained-regular and pause-build cells, exhibited prolonged outputs, whereas rebound cells with shorter time constants had shorter duration outputs. To examine how time constant affects the output/input ratio, we determined the slope of a linear fit of the relationship. The regression of the linear fit $(r)$ was 0.94 and its square $\left(r^{2}\right)$ was 0.88 . This suggests that the passive membrane time constant is the predominant factor $(88 \%)$ in determining the duration of the output of ICC neurons, at least when synaptic activity is evoked with single lemniscal shocks; however, other factors such as ion conductances activated during synaptic input also affect the output duration.

\section{Components of the synaptic input to ICC}

Although the net evoked PSP to a single lemniscal shock in the laminar slice was predominantly excitatory, it did not preclude the activation of inhibitory inputs. ICC neurons showed evidence of both inhibitory and excitatory inputs. Background activity observed in the absence of lemniscal stimulation commonly consisted of inhibitory synaptic potentials, subthreshold excitatory potentials, and action potentials (Fig. 4A). Inhibitory potentials (Fig. 4A, asterisks) could be seen alone, preceding or following action potentials, or in mixtures of excitatory and inhibitory potentials.

ICC neurons contain glutamatergic AMPA and NMDA receptors and inhibitory $\mathrm{GABA}_{\mathrm{A}}$ receptors (Ma et al. 2002a; Wu et al. 2004). We therefore examined the shaping of lemniscally evoked synaptic responses by excitatory and inhibitory inputs by means of selectively blocking AMPA, NMDA, and $\mathrm{GABA}_{\mathrm{A}}$ receptors. PSCs recorded under control conditions generally exhibited more than one component (Fig. 4B, bottom traces, asterisks). The NMDA-R antagonist APV $(100 \mu \mathrm{M})$ decreased PSC amplitude and duration (Fig. $4 \mathrm{~B}$, bottom traces; $n=$ $41)$. These effects were observed at holding potentials of $-60 \mathrm{mV}$ and indicate that NMDA receptors were activated at these relatively negative potentials.
A

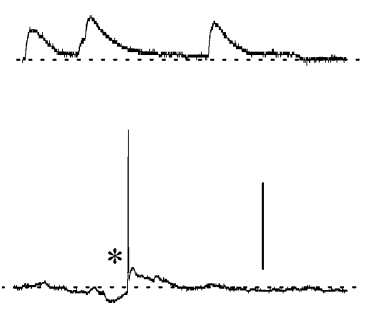

B
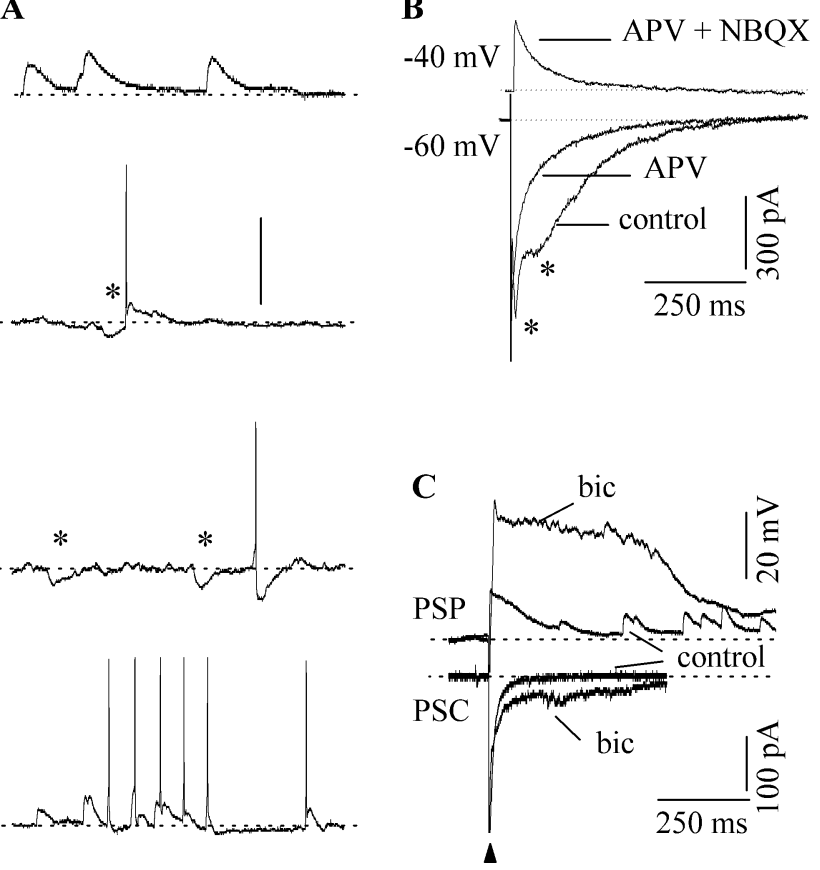

FIG. 4. Spontaneous and evoked responses. (A) Activity recorded under current-clamp in four neurons in normal saline in the absence of lemniscal stimulation. Each trace is from a different neuron. Resting potentials in the four cells were between -51 and $-54 \mathrm{mV}$. Asterisks indicate inhibitory potentials. (B) Voltage-clamp recordings of synaptic currents in a rebound-transient cell (P12) evoked by a 0.2-ms lemniscal shock in the conditions indicated. Holding potentials are indicated at the traces. APV $100 \mu \mathrm{M}, \mathrm{NBQX} 10 \mu \mathrm{M}$, bicuculline $30 \mu \mathrm{M}$. (C) Lemniscally evoked PSPs in a neuron (P14) in normal saline and in $30 \mu \mathrm{M}$ bicuculline. QX-314 (10 $\mu \mathrm{M})$ was present in the internal solution.

PSCs remaining in APV were abolished by the AMPA receptor antagonist NBQX (not shown here, but see Moore et al. 1998; Wu et al. 2004). Inhibitory (outward) PSCs were not observed at these holding potentials, but were apparent at slightly more positive holding potentials $(>-55 \mathrm{mV}$; Fig. $4 \mathrm{~B}$, top trace). In most cases, they were abolished by the $\mathrm{GABA}_{\mathrm{A}}$ antagonist, bicuculline.

Blocking $\mathrm{GABA}_{\mathrm{A}}$ receptors greatly increased the amplitude and duration of both the PSCs and PSPs seen after lemniscal stimulation. For example, Figure $4 \mathrm{C}$ shows both the potentials and currents from the same neuron after a single lemniscal shock. The same strength shock produced larger and more prolonged PSPs (Fig. 4C, top) and PSCs (Fig. 4C, bottom) in bicuculline than in control conditions. At maximum shock strengths, PSP amplitudes averaged across neurons increased by $\sim 160 \%$ in bicuculline. In normal saline they were $30 \pm 6 \mathrm{mV}(n=55)$ and were $48 \pm 8 \mathrm{mV}$ in $30 \mu \mathrm{M}$ bicuculline $(n=30)$. PSP durations increased by $\sim 200 \% \quad(852 \pm 186 \mathrm{~ms}$ in normal saline and $2.85 \pm 0.6 \mathrm{~s}$ in bicuculline). In addition to the increase in amplitude and duration, PSPs in bicuculline were characterized by a pro- 
longed plateau phase that often lasted for $500 \mathrm{~ms}$ or longer, depending on the shock strength.

\section{NMDA shapes sustained firing in ICC neurons}

NMDA synapses in ICC neurons were active at -60 $\mathrm{mV}$ and gave rise to subthreshold PSPs at these potentials $(n=16)$. Figure 5Ai illustrates the response of an ICC neuron to a lemniscal shock that evoked spiking in normal saline. When AMPA receptors were blocked with NBQX, the spiking was abolished, but a subthreshold PSP remained at the resting potential (Fig. 5Aii). This PSP was blocked by the NMDA-R antagonist APV $(100 \mu \mathrm{M})$ (Fig. 5Aiii). These results indicate that, at a resting membrane potential of -60 $\mathrm{mV}$, both NMDA and AMPA receptors are activated by lemniscal stimulation.

Blocking NMDA receptors limited lemniscally evoked sustained firing in ICC neurons. A sustained response evoked in normal saline (Fig. 5Bi) was reduced to an onset response in the presence of 100

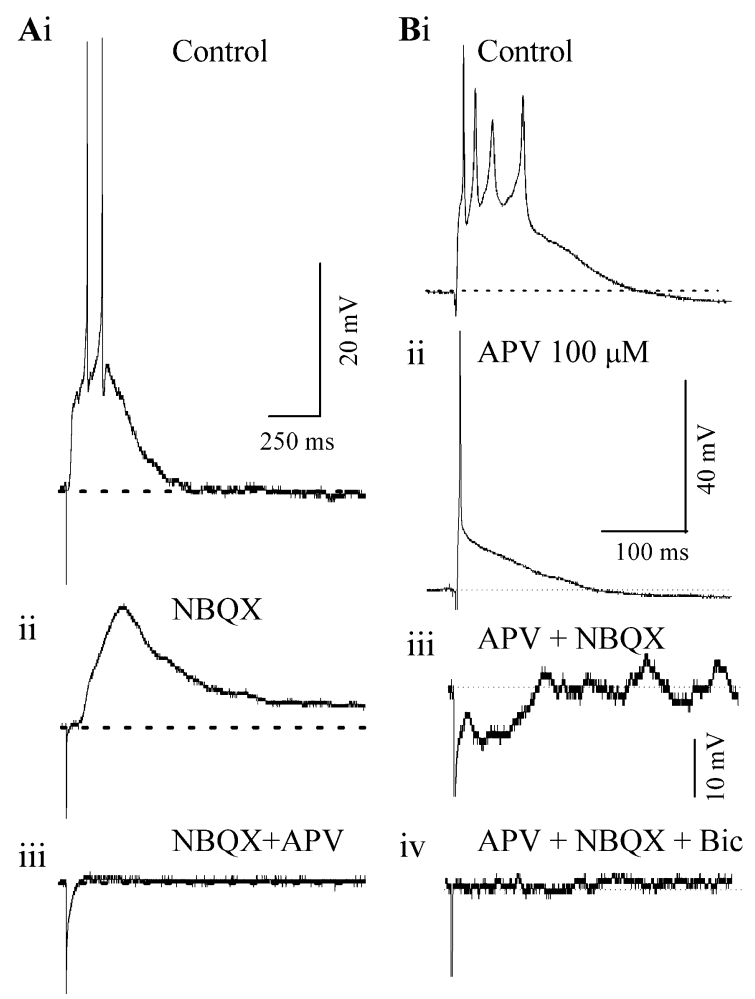

FIG. 5. AMPA and NMDA components of the postsynaptic response. (A) Isolation of NMDA-PSPs in the presence of $10 \mu \mathrm{M}$ NBQX in an ICC neuron at $-60 \mathrm{mV}$. A DC hyperpolarization was used to change the membrane potential to $-60 \mathrm{mV}$ from its resting potential of $-55 \mathrm{mV}$. (B) Effects of blocking NMDA receptors. Current-clamp recordings from a rebound-transient cell (P14) in response to a 0.5 -ms lemniscal shock. The shock strength was kept constant in (i)-(iv). Resting potential $=-50 \mathrm{mV}$. (Bi) normal saline, (Bii) $100 \mu \mathrm{M}$ APV, (Biii) $100 \mu \mathrm{M}$ APV + $10 \mu \mathrm{M}$ NBQX, (Biv) $100 \mu \mathrm{M}$ $\mathrm{APV}+10 \mu \mathrm{M}$ NBQX $+30 \mu \mathrm{M}$ bicuculline. $\mu \mathrm{M}$ APV (Fig. 5Bii). Further addition of NBQX abolished both the excitatory PSP and the single spike, and PSPs remaining in glutamatergic antagonists were predominantly inhibitory (Fig. 5Biii). The remaining PSP was sensitive to bicuculline (Fig. 5Biv). These results were observed in all ICC neurons tested $(n=42)$ and indicate that NMDA-mediated synaptic transmission mediates the long-duration PSP and enables sustained firing, whereas AMPA-mediated transmission appears to produce a shorter PSP that enables onset but not sustained responses to lemniscal stimulation. The prolonged plateau phase characteristic of the NMDA-mediated synaptic potential suggests that polysynaptic components are involved.

\section{Interaction of $\mathrm{NMDA}$ and $\mathrm{GABA}_{\mathrm{A}}$ receptors to regulate sustained firing}

When $\mathrm{GABA}_{\mathrm{A}}$ synapses were blocked, the unopposed activation of AMPA and NMDA receptors resulted in very large synaptic potentials that caused depolarization block and thus abolished firing. Figure 6 illustrates recordings from a cell in which lowintensity lemniscal stimulation evoked small, short PSPs and minimal firing in an ICC neuron in normal saline (Fig. 6Ai). The evoked PSP was greatly enhanced both in amplitude and duration when bicuculline was added to the bath (Fig. 6Aii, $n=$ 36). In this cell, the peak PSP amplitude and its total duration in normal saline were $11 \mathrm{mV}$ and $320 \mathrm{~ms}$, respectively (Fig. 6Ai), and $48 \mathrm{mV}$ and $1690 \mathrm{~ms}$ in bicuculline (Fig. 6Aii). Firing during this large PSP in bicuculline was restricted to one or two shortened spikes at the beginning of the PSP, followed by a complete depolarization block during the rest of the PSP (Fig. 6Aii).

If NMDA receptors were partially blocked with 50 $\mu \mathrm{M}$ APV, the PSP observed in bicuculline (Fig. 6Aii) decreased in duration and amplitude, and spiking was partially restored (Fig. 6Aiii). The bicuculline + $50 \mu \mathrm{M}$ APV solution slightly decreased the peak PSP amplitude ( 48 to $44 \mathrm{mV}$ ), but had a noticeable effect on the total duration of the PSP (1690 to $865 \mathrm{~ms}$ ) as well as the duration of the plateau phase (from 725 to $315 \mathrm{~ms}$ ) (Fig. 6Aiii). The decrease in amplitude and duration of the plateau potential was accompanied by a return of multiple spikes during the first $100-300 \mathrm{~ms}$ of the PSP as well as during its decay (Fig. 6Aiii).

The effect of APV on PSP duration and firing pattern was dependent on its concentration. Thus, when $\mathrm{GABA}_{\mathrm{A}}$ receptors were blocked and the APV concentration was increased to $100 \mu \mathrm{M}$, the duration of the PSP decreased further (from $865 \mathrm{~ms}$ in $50 \mu \mathrm{M}$ APV to $660 \mathrm{~ms}$ in $100 \mu \mathrm{M} \mathrm{APV}$ ) and the plateau potential was absent (Fig. 6Aiii). Because bicuculline 


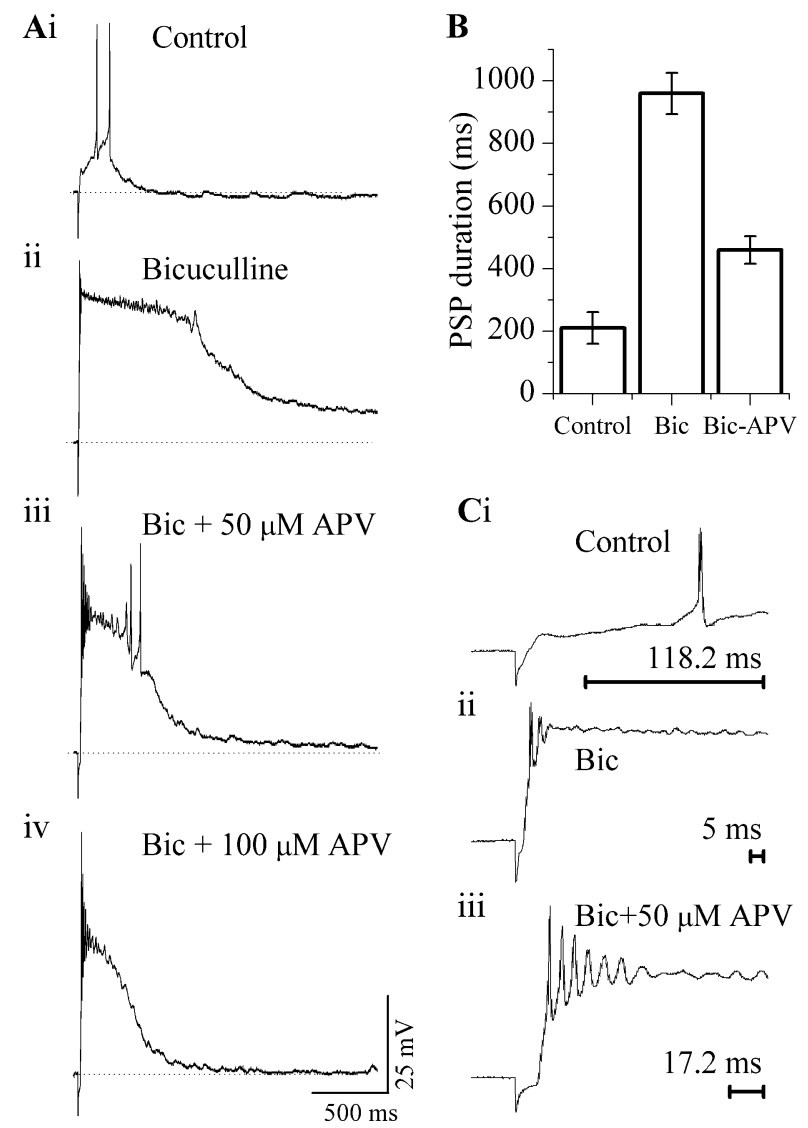

FIG. 6. Effects of NMDA and GABAA synapses on PSP duration and firing. (Ai) Lemniscal shock strength was adjusted to produce a small suprathreshold PSP in normal saline and shock strength was kept constant throughout. (Aii-iv) Effects of $30 \mu \mathrm{M}$ bicuculline and different APV concentrations. (B) Mean PSP durations (<SEM) for 24 neurons. Since the percent change in bicuculline or APV + bicuculline depended on the initial amplitude and duration of the PSP in normal saline, the control PSPs for this figure were taken as those evoked by the minimum stimulation required to produce one or two spikes in normal saline. APV $50 \mu \mathrm{M}$, bicuculline $30 \mu \mathrm{M}$. (C) Effect of bicuculline and APV on the latency of firing onset. Expansions of the initial portion of trace (i), (ii), and (iii) in (A). Scale bars indicate the latency of the first spike.

was present, the peak PSP amplitude was larger than in control conditions, but the lack of a plateau depolarization completely abolished sustained activity, and only an onset response remained (Fig. 6Aiv). Figure $6 \mathrm{~B}$ summarizes the effects of bicuculline and APV on PSP duration in 24 neurons. Blocking $\mathrm{GABA}_{\mathrm{A}}$ receptors causes a fivefold increase in PSP duration, and the block of NMDA receptors by $100 \mu \mathrm{M}$ APV counteracts this increased duration by $\sim 50 \%$.

Bicuculline and APV also affected the first spike latency (latency between the lemniscus stimulus artifact and the first spike in the ICC neuron). Figure 6C shows first spike latencies for the neuron in Figure 6A. Under control conditions, this latency was 118.2 ms (Fig. 6Ci). It decreased considerably, to $5 \mathrm{~ms}$, in bicuculline (Fig. 6Cii), and increased slightly, to 17.5 ms, when APV was also present (Fig. 6Ciii). In 14 cells measured, first spike latencies, at shock strengths that evoked subthreshold PSPs under control conditions, changed from $102 \pm 26$ ms under control conditions to $7 \pm 3.2 \mathrm{~ms}$ in bicuculline and $23 \pm 8 \mathrm{~ms}$ in APV. These changes in first spike latency are associated with changes in peak amplitude of the PSP under different conditions; thus, the slowly rising, smaller PSP evoked under control conditions produced a
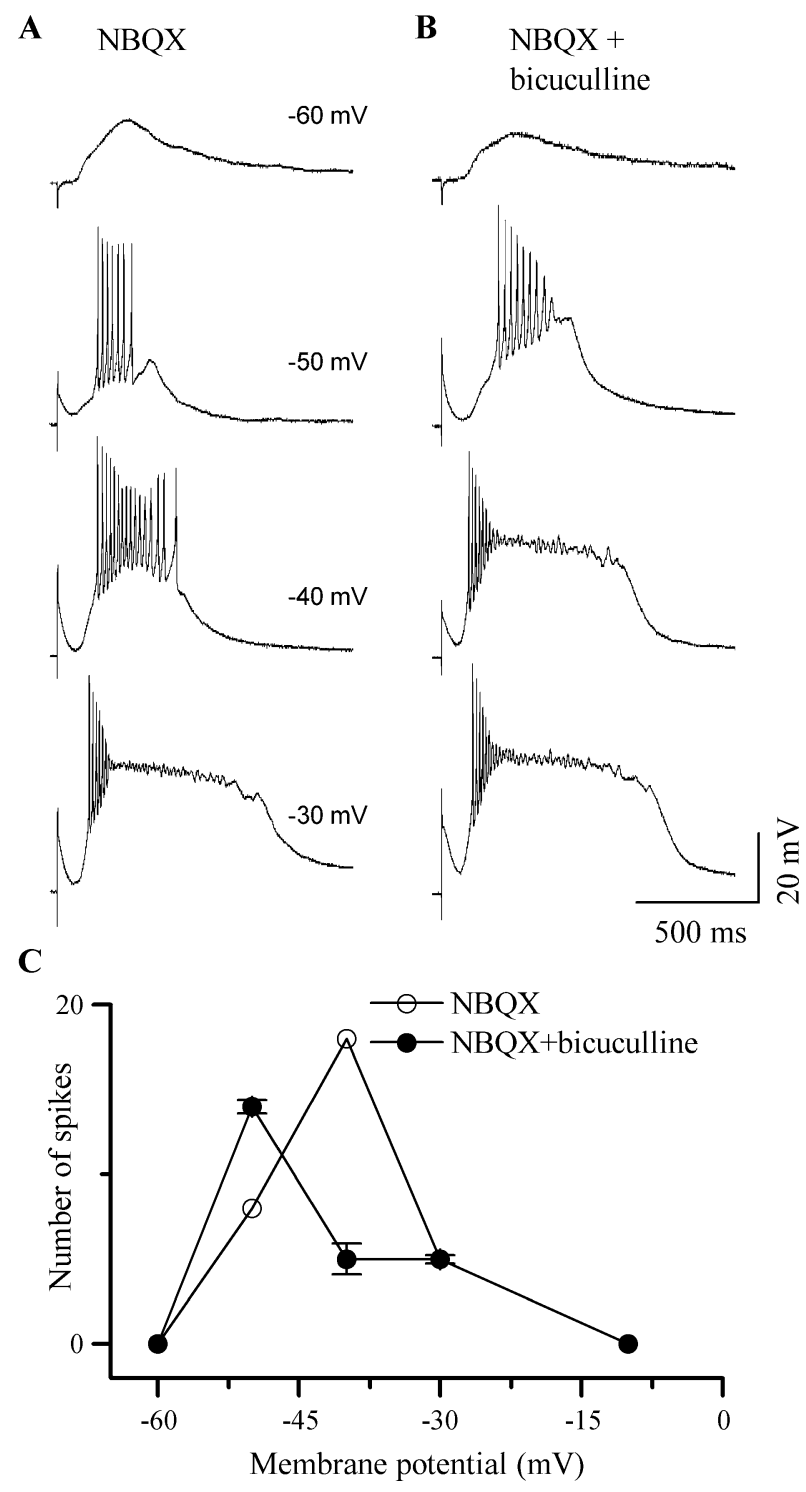

FIG. 7. The NMDA-GABAA balance affects the dynamic range of ICC neurons. (A, B) Responses of a sustained-regular cell (P15) to lemniscal stimulation in the presence of $10 \mu \mathrm{M}$ NBQX and $10 \mu \mathrm{M}$ NBQX $+50 \mu \mathrm{M}$ bicuculline. Stimulus strength and duration were kept constant, and the cell's membrane potential (indicated along each trace) was varied by passing DC current into the cell. (C) Plot of the total number of spikes as a function of membrane potential for 15 ICC neurons. Error bars represent SEM. 
long latency response, whereas the rapidly rising, large PSP obtained in bicuculline, produced the shortest first spike latency. The PSP evoked in bicuculline in the presence of a partial block of NMDA-Rs by $50 \mu \mathrm{M}$ APV had a lower peak amplitude than in bicuculline alone, thus the first spike latency was longer. A decrease in first spike latency in ICC in the presence of bicuculline has been shown to occur during sound stimulation in vivo (Pollak and Park 1993; Sivaramakrishnan et al. 2004).

$\mathrm{GABA}_{\mathrm{A}}$ receptor activation altered the voltage dependence of NMDA-mediated firing. When AMPA receptors were blocked with NBQX, subthreshold NMDA-mediated PSPs were observed at $-60 \mathrm{mV}$ (Fig. $7 \mathrm{~A}$, top trace). Changing the resting potential of the cell changed the amplitude and duration of the PSP as well as the firing pattern. The same shock strength that produced a subthreshold PSP at $-60 \mathrm{mV}$ (Fig. $7 \mathrm{~A}$, top trace) evoked sustained responses at -50 and $-40 \mathrm{mV}$ (Fig. 7A, second and third traces from top) and depolarization block at $-30 \mathrm{mV}$ (Fig. 7A, bottom trace). When $\mathrm{GABA}_{\mathrm{A}}$ receptors were blocked in addition to AMPA receptors (Fig. 7B), PSP amplitudes were larger and depolarization block occurred at less depolarized membrane potentials (e.g., -50
$\mathrm{mV}$; Fig. 7B, second trace from top). $\mathrm{GABA}_{\mathrm{A}}$ receptor activation caused a $20 \pm 4 \mathrm{mV}$ shift in the membrane potential at which maximum firing occurred and decreased the slope of the voltage dependence of firing (Fig. 7C; $n=15$ ).

These experiments suggest that a critical balance between NMDA and $\mathrm{GABA}_{\mathrm{A}}$ synapses is needed to maintain sustained firing in an ICC neuron during lemniscal input. In the absence of $\mathrm{GABA}_{\mathrm{A}}$ activation, NMDA-R activation causes large, prolonged depolarizations and firing block. In the complete absence of NMDA-R activation, AMPA-R mediated PSPs, although about $500 \mathrm{~ms}$ long, do not appear to have the plateau phase needed for sustained firing. Thus, NMDA synapses must be activated to produce a sustained response to a brief stimulus. $\mathrm{GABA}_{\mathrm{A}}$ synapses maintain the sustained response by keeping the amplitude and duration of the NMDA-mediated plateau potential below that which produces depolarization block.

\section{Responses of ICC neurons to stimulus trains}

When stimulus trains are used, response patterns were governed by a combination of train frequency
Ai

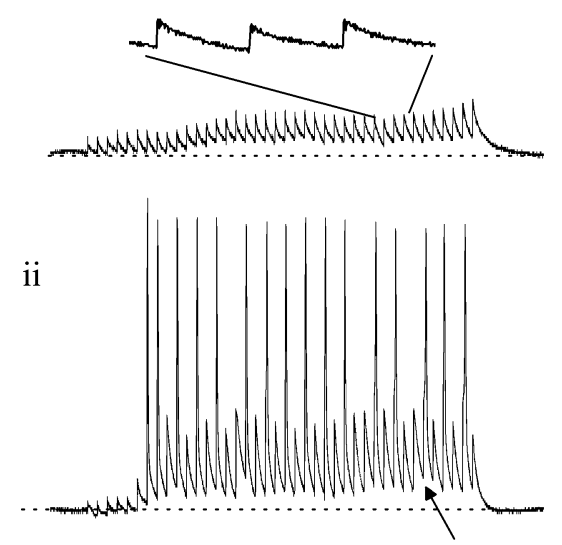

iii

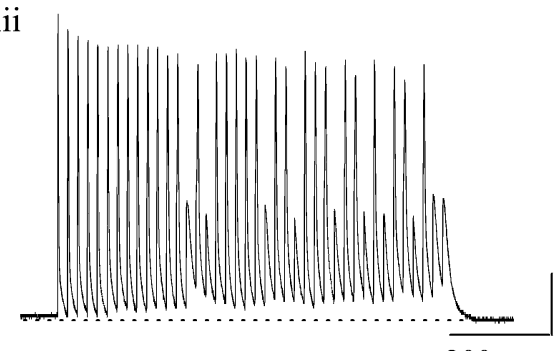

Bi

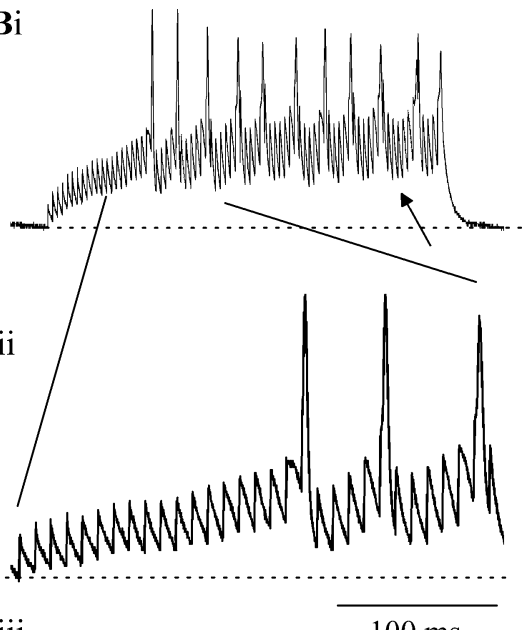

iii

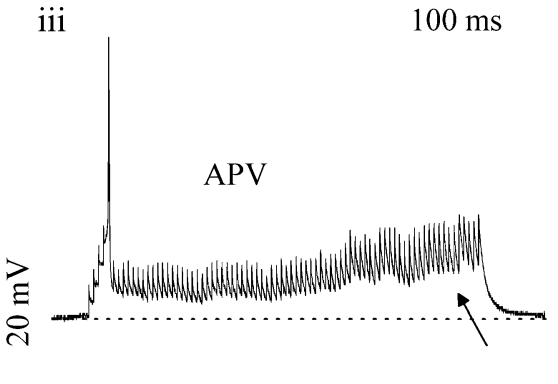

FIG. 8. Responses of ICC neurons to stimulus trains show sustained depolarization. (Ai-iii) Response in a rebound-regular neuron to a $50-\mathrm{Hz}$ train of lemniscal shocks in normal saline where the shock strength is increased from (i) to (iii). Expanded portion of the trace in (Ai) (inset). (Bi-ii) The same neuron as in (A) stimulated at $100 \mathrm{~Hz}$ in normal saline. (Bii) The trace from (Bi) expanded. (Biii) The same neuron in $100 \mu \mathrm{M} \mathrm{APV}$ stimulated at $100 \mathrm{~Hz}$ at the same shock strength as $(\mathrm{Bi})$. Age P15. Scale bars $=200 \mathrm{~ms}$ for all traces except $\mathrm{Ai}$ inset and Bii where the scale bar is $100 \mathrm{~ms}$. 
and shock strength. For example, the responses of an ICC neuron are illustrated at two train frequencies, $50 \mathrm{~Hz}$ (Fig. 8A) and $100 \mathrm{~Hz}$ (Fig. 8B). Low shock strengths could evoke subthreshold responses throughout the train (Fig. 7Ai and inset) with responses becoming suprathreshold as shock strength was increased (Fig. 8Aii, iii). At $50 \mathrm{~Hz}$, most PSPs in the train resulted in a spike at the higher shock strengths, so that firing was sustained during the entire train (Fig. 8Aiii). The sustained response consisted of a maximum of one spike/PSP during the train (Fig. 8Aiii).

At $100 \mathrm{~Hz}$, spiking did not occur in response to every PSP (Fig. 8Bi). Spikes were evoked only once every 3-5 PSPs. The PSP amplitude gradually increased with each stimulus during the train until a spike was evoked; following the spike, PSP amplitudes decreased, and then increased again until the next spike occurred (Fig. 8Bii; $n=16$ ). Thus, during highfrequency trains, PSP amplitudes generated by each stimulus in the train are not large enough to evoke spikes, and PSP summation is necessary for spiking. This result contrasts with the spiking patterns observed during lower frequency trains, when, at similar shock strengths, each PSP during the train is large enough to evoke spikes (e.g., Fig. 8Aiii). ICC neurons thus appear to be able to follow lower frequency stimulus trains more faithfully.

Spikes and PSPs during stimulus trains were generally accompanied by an accumulating depolarization that increased during the train (arrows, Figs. 8Aii and $\mathrm{Bi}$, iii). This depolarization was substantially reduced by the addition of $100 \mu \mathrm{M}$ APV (compare Fig. $8 \mathrm{Bi}$ and iii, arrows). The sustained firing observed during both 50 - and $100-\mathrm{Hz}$ trains was also abolished by $100 \mu \mathrm{M}$ APV (e.g., Fig. 8Biii; $n=8$ ). Responses in APV were characterized by a single spike at the beginning of the train with little spiking during the rest of the train (Fig. 8Biii). Similar to responses observed with single lemniscal shocks, these results indicate that the ability to generate a sustained response during a train of shocks is also dependent on the accumulating or plateau potential generated by NMDA-R activation.

\section{DISCUSSION}

We have used the laminar brain slice to examine synaptic potentials and firing patterns of ICC neurons initiated by stimulation of the lateral lemniscus. The main findings are that increasing levels of lemniscal stimulation result in excitatory postsynaptic potentials with increasing duration, amplitude, and a prominent plateau phase. The plateau potential is an NMDA-mediated potential whose amplitude and duration are regulated by $\mathrm{GABA}_{\mathrm{A}}$ activation. A similar NMDA-mediated accumulating potential is seen after stimulus trains. The plateau potential provides a sustained depolarization following or during lemniscal input, and thus enables an ICC neuron to produce sustained firing. As the duration and amplitude of the plateau potential are regulated by the balance between NMDA-R and GABA $_{A}-\mathrm{R}$ activation, this balance is also primarily responsible for the sustained activity evoked by lemniscal stimulation. In half the ICC neurons examined, the synaptic potential is much longer that the synaptic current, whereas in the remaining population, the synaptic potential duration is similar to the current. These data suggest that in the intact laminae of the ICC, lemniscal inputs initiate sustained firing through monosynaptic and polysynaptic NMDA-mediated synapses regulated by $\mathrm{GABA}_{\mathrm{A}}$ synapses.

It may be difficult to drive neurons in ICC monosynaptically by stimulation of the lateral lemniscus in the transverse plane (Wagner 1996). The laminar slice used in this study parallels the fibrodendritic laminae of the ICC, does not cut lemniscal fibers, and allows distal stimulation of the lemniscal afferents (Figs. 1B-C). This allows monosynaptic activation of ICC neurons while avoiding the direct activation of local axons in ICC. In this sense, it is similar to the parasagittal slice frequently used in brain slice experiments of the cochlear nucleus that permits distal stimulation of the eighth nerve without direct stimulation of local axons of the cochlear nucleus (Oertel 1983).

\section{Factors contributing to plateau potentials and} sustained firing in ICC slice

Our observations may be partially attributed to the spatial and temporal recruitment of lemniscal fibers afforded by the laminar slice plane. Previous studies of ICC in the rat, gerbil, and mouse did not report PSP durations as long as in the present report, nor did they report sustained firing in response to lemniscal stimulation (Wagner 1996; Moore et al. 1998; Ma et al. 2002a). In the present study, the slice plane allows more of the dendritic tree to remain intact, and the lemniscal fibers that course parallel to the lamina/dendrites also remain intact. This may preserve the multiple, en passant, axodendritic synapses from lemniscal axons that terminate on ICG neurons (Oliver et al. 1995; Oliver et al. 1999). Consequently, the stimulation of a single lemniscal axon may be more effective because more of its inputs to a single neuron may be preserved. As there are more intact lemniscal fibers to be stimulated distally, the sustained potentials and firing we observe may result from an ability to recruit more axons than 
in the other configuration. Thus, both increasing numbers of inputs and temporal summation of these inputs may contribute to our findings.

The preservation of local connections within a layer may be a second factor contributing to plateau potentials that support sustained firing. Connections within single layers (intralaminar) as well as connections between layers (interlaminar) have been described by Golgi and intracellular labeling techniques (Morest and Oliver 1984; Oliver et al. 1991). In the present experiments, with the slice parallel to the layers, intralaminar connections may be especially well preserved. Although the lemniscal fibers are stimulated distal to ICC and contribute monosynaptic inputs, other lemniscally activated neurons may also contribute inputs to our recorded cells via intralaminar connections (Fig. 1D). Future experiments are needed to separate the monosynaptic and polysynaptic inputs to ICC neurons.

A third factor contributing to sustained firing in the laminar ICC slice is the NMDA-mediated current. The net excitation that results when both excitatory and inhibitory lemniscal inputs are activated is consistent with findings that $\sim 60 \%$ of ICC synapses have the morphology associated with glutamate synapses (reviewed in Oliver 2000). Glutamatergic synapses account for most of the depolarization after lemniscal stimulation in gerbil and mouse ICC (Wagner 1996; Moore et al. 1998). In the rat, the glutamatergic currents have been resolved into fast AMPA- and slow NMDA-mediated components (Ma et al. 2002a; Wu et al. 2004). Unlike the mouse (Wagner 1996), the NMDA component in the rat ICC is capable of activation near resting potentials (Wu et al. 2004; our present study), and action potentials can be produced in the absence of AMPA (Fig. 5). The present findings show that the AMPA current contributes to onset potentials and onset firing, whereas the NMDA current contributes to the sustained component of the PSP or the accumulating depolarizations seen during single stimuli or trains of stimuli (Figs. 5, 6, 7, and 8). The AMPA current alone is insufficient to maintain sustained firing with single lemniscal shocks or with trains of shocks.

The relative contributions of AMPA and NMDA receptors to ICC neuronal firing is likely to be affected both by the age of the experimental animal as well as by inherent technical limitations. NMDA currents are somewhat larger in young animals (Ramoa and McCormick 1994), and some reports indicate that in the ICC, the AMPA/NMDA ratio may stabilize after postnatal day 12 (Wu et al. 2004). AMPA and NMDA receptor subunit expression undergo age-dependent modifications in the rat ICC. For example, the expression of the NMDA
NR2D subunit, which is particularly involved with prolonged depolarizations, decreases 3 weeks after birth (Wenzel et al. 1996; Caicedo and Eybalin 1999). Thus, NMDA-R currents are likely to be less prolonged in adults; however, in vivo studies in the rat ICC show that both AMPA and NMDA receptors are involved in auditory processing. Thus, although our results were obtained in juvenile animals, they are consistent with in vivo studies (see discussion below).

Our results indicate that the NMDA-R current is active at relatively hyperpolarized membrane potentials $(-60 \mathrm{mV})$. This finding might be partly attributable to the inadequate space clamp of ICC neurons; however, NMDA-R activation at resting membrane potentials occurs even when AMPA receptors are blocked (Fig. 7), suggesting that an inadequate space clamp is not entirely responsible for this observation. A low threshold of activation is more likely to be a result of a reduced sensitivity of NMDA receptors to $\mathrm{Mg}^{2+}$ block in juvenile animals (Kato and Yoshimura 1993).

$\mathrm{GABA}_{\mathrm{A}}$ synapses are a key factor in the regulation of the NMDA-mediated plateau potential and sustained firing. Under normal conditions, the duration of the NMDA-R potential is limited by the activation of $\mathrm{GABA}_{\mathrm{A}}$ synapses. GABAergic inhibition is more pronounced at more depolarized membrane potentials, e.g., $-40 \mathrm{mV}$, than at rest, and it would therefore be a primary regulator of the NMDA-R response at higher potentials. If $\mathrm{GABA}_{\mathrm{A}}$ inhibition is absent, the NMDA-mediated potential can be longer, and firing may increase up to the point where the NMDA potential is so high that the cell stops firing due to depolarization block (Fig. 6Aii-iii). This excitationinhibition balance is an important determinant of responses to sound intensity in the ICC (Sivaramakrishnan et al. 2004).

Postsynaptic mechanisms are a final factor contributing to the plateau potentials and sustained firing, both with single shocks and with input trains. Measurements of the PSP/PSC ratio suggest two modes of response in ICC neurons, as half the neurons had PSPs that were three to four times longer than the PSC. Neurons in the ICC differ in terms of intrinsic membrane properties and potassium conductances (Sivaramakrishnan and Oliver 2001) as well as in the density of hyperpolarizationactivated cation currents (Koch and Grothe 2003). Our results further indicate that an inability of ICC neurons to follow high-frequency inputs in vivo (Rees and Moller 1983; Langner and Schreiner 1988; Gooler and Feng 1992) might also result from slow membrane time constants, which prevent PSPs from reaching threshold at short interspike intervals. This suggests that the ICC is made up of cells with different combinations of passive and active mem- 
brane properties, which causes a mismatch between the output and the input for some neurons, but a close correlation in other neurons.

\section{Implications for the regulation of firing in the ICC in vivo}

A sustained depolarization is often seen in the ICC during intracellular recordings in vivo. An underlying depolarization is seen in response to almost every acoustic stimulus unless there is a net inhibitory IPSP (Torterolo et al. 1995; Kuwada et al. 1997; Pedemonte et al. 1997). Likewise, spikes ride on a sustained inward current in voltage-clamp recordings in vivo (Covey et al. 1996). These synaptic responses have not been dissected pharmacologically; however, a number of studies with extracellular recordings point to the importance of NMDA-mediated potentials for responses to sound in ICC (Burger and Pollak 1998; Zhang and Kelly 2001). For example, when neurons with sustained responses in the adult rat are exposed to NMDA antagonists, there is a marked decrease in the later part of the response (>20 ms) (Zhang and Kelly 2001).

A prolonged depolarization produced by NMDA-R activation could serve to increase response efficiency in the ICC. Unlike a calyx or endbulb ending that has multiple active zones from only one or two presynaptic axons, many axons may converge on a single ICC neuron (Oliver et al. 1999). Consequently, recruitment of multiple inputs is probably required to produce sustained firing to acoustic stimuli. The underlying NMDA-mediated potential may substantially increase the firing probability in ICC neurons and increase the efficiency of the system. Because of NMDA-R activation, fewer input axons may need to be recruited to evoke sustained firing in an ICC neuron.

Under normal conditions, the level of NMDA activation may be mediated by $\mathrm{GABA}_{\mathrm{A}}$ receptors in the ICC, and the loss of this control mechanism may underlie seizure activity. Plateau potentials are seen in other regions of the CNS, such as the thalamus (Jahnsen and Llinas 1984), hippocampus (Dingledine et al. 1986), motorneurons (Kim and Chandler 1995), and cortical pyramidal cells (Schwindt and Crill 1998), and they are usually associated with sustained or bursting firing patterns. Dingledine et al. (1986) performed a similar experiment in CA1 of hippocampus, where APV reduced the plateau potential of a pyramidal cell when bicuculline was present and removed the late component of the EPSP. As in ICC, the balance of excitation by NMDA receptors and inhibition due to $\mathrm{GABA}_{\mathrm{A}}$ receptors is the key mechanism to regulate hippocampal excitability (Dingledine et al. 1986). When regulation by
GABA synapses is lost, epileptiform bursting occurs (Dingledine et al. 1986; Smith 1992; Wagner 1996), and this may be related to pathological seizure activity in both ICC (Smith 1992; Li et al. 1994) and the hippocampus (Coulter 2001; Avoli et al. 2002; Nadler 2003).

\section{ACKNOWLEDGEMENTS}

This work was supported by NIH grant RO1-DC00189.

\section{REFERENCES}

Adams JC. Ascending projections to the inferior colliculus. J. Comp. Neurol. 183:519-538, 1979.

Avoli M, D’Antuono M, Louvel J, Kohling R, Biagini G, Pumain R, D'Arcangelo G, Tancredi V. Network and pharmacological mechanisms leading to epileptiform synchronization in the limbic system in vitro. Prog. Neurobiol. 68:167-207, 2002.

Bal R, Green GG, Rees A, SAnders DJ. Firing patterns of inferior colliculus neurons-histology and mechanism to change firing patterns in rat brain slices. Neurosci. Lett. 317:42-46, 2002.

Burger RM, Pollak GD. Analysis of the role of inhibition in shaping responses to sinusoidally amplitude-modulated signals in the inferior colliculus. J Neurophysiol. 80:1686-1701, 1998

Caicedo A, Eybalin M. Glutamate receptor phenotypes in the auditory brainstem and mid-brain of the developing rat. Eur. J. Neurosci. 11:51-74, 1999.

Casseday JH, Ehrlich D, Covey E. Neural measurement of sound duration: control by excitatory-inhibitory interactions in the inferior colliculus. J. Neurophysiol. 84:1475-1487, 2000.

Coulter DA. Epilepsy-associated plasticity in gamma-aminobutyric acid receptor expression, function, and inhibitory synaptic properties. Int. Rev. Neurobiol. 45:237-252, 2001.

Covey E, Kauer JA, Casseday JH. Whole-cell patch-clamp recording reveals subthreshold sound-evoked postsynaptic currents in the inferior colliculus of awake bats. J. Neurosci. 16:3009-3018, 1996.

Dingledine R, Hynes MA, King GL. Involvement of $N$-methyl-Daspartate receptors in epileptiform bursting in the rat hippocampal slice. J. Physiol. 380:175-189, 1986.

Faingold CL, Anderson CA, Randall ME. Stimulation or blockade of the dorsal nucleus of the lateral lemniscus alters binaural and tonic inhibition in contralateral inferior colliculus neurons. Hear Res. 69:98-106, 1993.

Faye-Lund H, Osen KK. Anatomy of the inferior colliculus in rat. Anat. Embryol. 171:1-20, 1985.

GoOler DM, Feng AS. Temporal coding in the frog auditory midbrain: the influence of duration and rise-fall time on the processing of complex amplitude-modulated stimuli. J. Neurophysiol. 67:1-22, 1992.

JAHNSEN H, Llinas R. Electrophysiological properties of guinea-pig thalamic neurones: an in vitro study. J. Physiol. 349:205-226, 1984.

Kato N, Yoshimura, H. Reduced $\mathrm{Mg}^{2+}$ block of $\mathrm{N}$-methyl-D-aspartate receptor-mediated synaptic potentials in developing visual cortex. Proc. Natl. Acad. Sci. USA 90:7114-7118, 1993.

Khawaled R, Bruening-Wright A, Adelman JP, Maylie J. Bicuculline block of small-conductance calcium-activated potassium channels. Pflugers Arch. 438:314-321, 1999.

KIM YI, CHANDLER SH. NMDA-induced burst discharge in guinea pig trigeminal motoneurons in vitro. J. Neurophysiol. 74:334-346, 1995. 
Kосн U, Grothe B. Hyperpolarization-activated current $\left(I_{\mathrm{h}}\right)$ in the inferior colliculus: distribution and contribution to temporal processing. J. Neurophysiol. 90:3679-3687, 2003.

KraushaAr U, Backus KH. Characterization of GABA(A) and glycine receptors in neurons of the developing rat inferior colliculus. Pflugers Arch. 445:279-288, 2002.

Kuwada S, Batra R, Yin TC, Oliver DL, Haberly LB, Stanford TR. Intracellular recordings in response to monaural and binaural stimulation of neurons in the inferior colliculus of the cat. J. Neurosci. 17:7565-7581, 1997.

Langner G, Schreiner CE. Periodicity coding in the inferior colliculus of the cat. I. Neuronal mechanisms. J. Neurophysiol. 60:1799-1822, 1988.

Le Beau FE, Rees A, Malmierca MS. Contribution of GabA- and glycine-mediated inhibition to the monaural temporal response properties of neurons in the inferior colliculus. J. Neurophysiol. 75:902-919, 1996.

LI Y, Evans MS, FaINGOLd CL. Inferior colliculus neuronal membrane and synaptic properties in genetically epilepsy-prone rats. Brain Res. 660:232-240, 1994.

Li Y, Evans MS, Faingold CL. In vitro electrophysiology of neurons in subnuclei of rat inferior colliculus. Hear Res. 121:1-10, 1998

Li Y, Evans MS, Faingold CL. Synaptic response patterns of neurons in the cortex of rat inferior colliculus. Hear Res. 137:15-28, 1999.

Loftus WC, Bishop DC, SaintMarie RL, Oliver DL. Organization of binaural excitatory and inhibitory inputs to the inferior colliculus from the superior olive. J. Comp. Neurol. 472:330344,2004

MA CL, Kelly JB, Wu SH. AMPA and NMDA receptors mediate synaptic excitation in the rat's inferior colliculus. Hear Res. 168:25-34, 2002a.

Ma CL, Kelly JB, Wu SH. Presynaptic modulation of GABAergic inhibition by $\mathrm{GABA}(\mathrm{B})$ receptors in the rat's inferior colliculus. Neuroscience 114:207-215, 2002b.

Malmierca MS, Blackstad TW, Osen KK, Karagulle T, Molowny RL. The central nucleus of the inferior colliculus in rat: a Golgi and computer reconstruction study of neuronal and laminar structure. J. Comp. Neurol. 333:1-27, 1993.

Moore DR, Kotak VC, SANES DH. Commissural and lemniscal synaptic input to the gerbil inferior colliculus. J. Neurophysiol. 80:2229-2236, 1998.

Morest DK, Oliver DL. The neuronal architecture of the inferior colliculus in the cat: defining the functional anatomy of the auditory midbrain. J. Comp. Neurol. 222:209-236, 1984.

NADLER JV. The recurrent mossy fiber pathway of the epileptic brain. Neurochem. Res. 28:1649-1658, 2003.

N'Gouemo P, Morad M. Ethanol withdrawal seizure susceptibility is associated with upregulation of L- and P-type $\mathrm{Ca}^{2+}$ channel currents in rat inferior colliculus neurons. Neuropharmacology 45:429-437, 2003.

Oertel D. Synaptic responses and electrical properties of cells in brain slices of the mouse anteroventral cochlear nucleus. J. Neurosci. 3:2043-2053, 1983.

OlIVER DL. Ascending efferent projections of the superior olivary complex. Microsc. Res. Tech. 51:355-363, 2000.

Oliver DL, Huerta MF. Inferior and superior colliculi. In: Webster DB, Popper AN, Fay RR (eds) The mammalian auditory pathway: neuroanatomy, 1st ed. Springer-Verlag, New York, pp 168-221, 1992.

Oliver DL, Beckius GE, Shneiderman A. Axonal projections from the lateral and medial superior olive to the inferior colliculus of the cat: a study using electron microscopic autoradiography. J. Comp. Neurol. 360:17-32, 1995.

Oliver DL, Ostapoff EM, Beckius GE. Direct innervation of identified tectothalamic neurons in the inferior colliculus by axons from the cochlear nucleus. Neuroscience 93:643-658, 1999.

Oliver DL, Kuwada S, Yin TC, Haberly LB, Henkel CK (1991) Dendritic and axonal morphology of HRP-injected neurons in the inferior colliculus of the cat. J. Comp. Neurol. 303: $75-100$.

Palombi PS, Caspary DM. GABA inputs control discharge rate primarily within frequency receptive fields of inferior colliculus neurons. J. Neurophysiol. 75:2211-2219, 1996.

PARK TJ, Pollak GD. GABA shapes sensitivity to interaural intensity disparities in the mustache bat's inferior colliculus: Implications for encoding sound location. J. Neurosci. 13:2050-2067, 1993.

Park TJ, Pollak GD. GABA shapes a topographic organization of response latency in the mustache bat's inferior colliculus. J. Neurosci. 13:5172-5187, 1993.

Pedemonte M, Torterolo P, Velluti RA. In vivo intracellular characteristics of inferior colliculus neurons in guinea pigs. Brain Res. 759:24-31, 1997.

Peruzzi D, Sivaramakrishnan S, Oliver DL. Identification of cell types in brain slices of the inferior colliculus. Neuroscience 101:403-416, 2000.

POlLAK GD, PARK TJ. The effects of GABAergic inhibition on monaural response properties of neurons in the mustache bat's inferior colliculus. Hear Res. 65:99-117, 1993.

RAmoa AS, McCormick DA. Enhanced activation of NMDA receptor responses at the immature retinogeniculate synapse. J. Neurosci. 14:2098-2105, 1994.

Rees A, Moller AR. Responses of neurons in the inferior colliculus of the rat to AM and FM tones. Hear. Res. 10: 301-330, 1983.

Riquelme R, Saldaña E, Osen KK, Ottersen OP, Merchán MA. Colocalization of GABA and glycine in the ventral nucleus of the lateral lemniscus in rat: an in situ hybridization and semiquantitative immunocytochemical study. J. Comp. Neurol. 432:409-424, 2001.

Saint Marie RL, Ostapoff EM, Morest DK, Wenthold RJ. Glycineimmunoreactive projection of the cat lateral superior olive: possible role in midbrain ear dominance. J. Comp. Neurol. 279:382-396, 1989.

SCHREINER CE, LANGNER, G. Laminar fine structure of frequency organization in auditory midbrain. Nature 388:383-386, 1997.

Schwindt PC, CriLl WE. Synaptically evoked dendritic action potentials in rat neocortical pyramidal neurons. J. Neurophysiol. 79:2432-2446, 1998.

Shneiderman A, Chase, MB, Rockwood, JM, Benson, CG, Potashner, SJ. Evidence for a GABAergic projection from the dorsal nucleus of the lateral lemniscus to the inferior colliculus. J. Neurochem. 60:72-82, 1993.

Sivaramakrishnan S, Oliver DL. Distinct $\mathrm{K}$ currents result in physiologically distinct cell types in the inferior colliculus of the rat. J. Neurosci. 21:2861-2877, 2001.

Sivaramakrishnan S, Sterbing-D'Angelo SJ, Filipovic B, D'Angelo, WR, Oliver, DL, Kuwada, S. GABA(A) synapses shape neuronal responses to sound intensity in the inferior colliculus. J. Neurosci. 24:5031-5043, 2004.

SмIтH PH. Anatomy and physiology of multipolar cells in the rat inferior collicular cortex using the in vitro brain slice technique. J. Neurosci. 12:3700-3715, 1992

Torterolo P, Pedemonte M, Velluti RA. Intracellular in vivo recording of inferior colliculus auditory neurons from awake guinea-pigs. Arch. Ital. Biol. 134:57-64, 1995

WAGNER T. Lemniscal input to identified neurons of the central nucleus of mouse inferior colliculus: an intracellular brain slice study. Eur. J. Neurosci. 8:1231-1239, 1996.

Wenzel A, Villa M, Mohler H, Benke D. Developmental and 
regional expression of NMDA receptor subtypes containing the NR2D subunit in rat brain. J. Neurochem. 66:1240-1248, 1996. Wu SH, Ma CL, Kelly JB. Contribution of AMPA, NMDA, and GABA(A) receptors to temporal pattern of postsynaptic responses in the inferior colliculus of the rat. J. Neurosci. 24:4625-4634, 2004.
Wu SH, Ma CL, Sivaramakrishnan S, Oliver DL. Synaptic modification in neurons of the central nucleus of the inferior colliculus. Hear. Res. 168:43-54, 2002.

Zhang H, KeLly JB. AMPA and NMDA receptors regulate responses of neurons in the rat's inferior colliculus. J. Neurophysiol. 86:871-880, 2001. 